symptoms; the abdominal distension; the diminished size of the liver; the occurrence of oedema; the thin bones; the muscular feebleness, and its afebri!e nature. All have their eonnterpart in animals subjected to vitaminic deficiency under experimental conditions. It may be, therefore, that a study of the malady from the vitaminic point of view might throw further light on its causation and treatment.

In this lecturo I have dealt only with deficient intake of vitamines as the cause of "deficiency disease." But it is possible that deficient assimilation of these substancesconsoquent on derangements of the digestive organs from whatere: cause arising-may give rise to symptoms of deficiency disease. It has seemed to me that solutions of vitamines have improved cases of enfeebled digestion and of biliary and pancreatic insufficiency more certainly than have the natural foods from which the solutions of vitamines 'were prepared.

There is much that I have been compelled to omit in so brief a consideration of the subject as this: amenorrhoea, sterility, inability of women to suckle their children, the effects on breast-fed infauts of human milk deficient in vitamines, dental caries, rickets, beri-beri, oedemas, and the special effects of vitaminic deficiency on the endocrine orgays. All these and much more are deserving of the closest study in connexion with the great question of diet as a factor in the causation of disease and racial degeneration. There is, indeed, no more important problem before the country at the present moment than the proper provision to the people of a properly constituted food, and no more urgent necessity than their instruction in these matters. I hope, however, that I have said enough to excite interest in the wider aspects of "deficiency disease," for I $\mathrm{om}$ convinced that with our increasing mastery of these dictetic problems our mastery orer disease will increase also.

\section{POISONING BY ARSENIUREITED HYDROGEN.} BY

THOMAS H. WIGNALL, M.B., B.S.VICT., MANCHESTER.

Textвooks dealing with industrial processes in which metals in gaseous combination are involved geneially do not rive definite facts as to minimum quantities capable of causing rapid deatl by toxaemia. Of course such data cannot be concise because of individual idiosyncrasy and the varying strength of gas acting lethally. My experience, therefore, in dealing with a particular example of this class-namely, poisoning by arseniuretted lyydrogen, $\mathrm{AsH}_{3}$ - may therefore be of interest.

'This gas, which possesses by weight a considerable proportion of arsenic and is of an acid type (not actually corrosire but resembling $\mathrm{H}_{2} \mathrm{~S}$ ), is chietly met with by workers on p:ocesses in which nascent hydrogen is liberated, or in which hydrogen is used as a gas-by lead burners or for the inflation of balloons or airships. Where hydrogen is derived from the interaction of a metal and an acid or alkali, cither one or both may contain large amounts of arsenic, and under these conditions the hydrogen is very liable to be contaminated by $\mathrm{AsH}_{3}$. In the process of reducing certain benzene derivatises from ope stage to another, zinc dust (or iron filings) is mixed with weak hydrachloric acid and ice in the presence of the body to be reduced; in another method zinc dust is heated with a caustic so'ution in tubs, vats, or pans. These materials frequently contain arsenic as an impurity, and this combining vith the hydrogen produced is inhaled by the workmen. 'The same gas may also occur in drains or wells where chemical fluids can accumulate.

Dr. Alice Hamilton, of the Labou' Bureau, New York, in her recert monograph, Hygienic Control of the Aniline Dye Industry in Jurope, published as a result of a tour over many British and Continental chemical works, quotes the statement in Rambous ''.'s well-known work on industwial poisoning, that the hundredth part of a milligram of As taken in the serm of arseniur atted hydrogen is rapidly fatal to human beings. My experience, which has extended over two years, shows, on the contraby, that much more than tisis amount can be taken and although the result is serious, if it not necessarily fatal
I have only met with one case in which death might actually be due to this cause.

This man was seen by me only a fer days preceding death. There were obviously present some of the leading symptoms, such as icterus and a low typhoid type of delirium, but the urine was not available for analytical purposes.

Post mortem the macroscopic appearance of main organs had no distinctive features, but as the man had worked on a reducing process it was inferred that death was due to toxaemia. specimens of viscera for analysis were obtained but not reported upon.

In subsequent cases which I saw from the onset, there werc symptoms which at once directed attention to the causative agent. Where a haematuria of porter-like appearance occurred, a quantitative test of the urine for arsenic was immediately made; all the men working on or near the process were examined carefully and their urine was submitted to investigation. By this means a few men were found to be excreting arsenic in the urine while not appearing ill and continuing at work in the ordinary way. The possibility of these men having ingested the arsenic in food or on unclean hands was considered, but proved untenable.

Arseniuretted hydrogen when inhaled in toxic amounts rapidly produces haemolysis, with destruction of the red corpuscles and conversion of haemoglobin into methaemoglobin and oxyhaemoglobin; there is a destructive effect on renal tubules and epithelium, and haematuria results. The daily output of urine is not necessarily reduced, and such cases do not always during the first ferv days feel ill enough to stop work; thus they may present themselves already having an icteric appearance, complaining of languor and anorexia and having a rapid feeble pulse of tension below $100 \mathrm{~mm}$. Hg. Such cases sent at once to hospital and notified as suffering from this gas toxaemia have invariably recovered, and the urine in the course of three to four weelss has ceased to contain more than what may be considered normal amounts of arsenic.

Not any of the workers on this process has to my knowledge developed nerre lesions, such as peripheral neuritis, known to follow the talking of excessive amounts - of arsenic by the mouth, nor has any splenic abnormality, icterus, nor biliary obstruction of any type remained as a subsequent feature.

From the amount of arseuic excreted by the urine over the pericd of detention in hospital-say, three to four weeks-it is easy to conclude that a far greater amount of this gas may be taken by inhalation without causing death than has hitherto been believed possible. Naturally the factors of concentration or dilution of gas, in any given case, are unknown; in men examined every tiventy-one days the period of absorption is limited to less thau three weeks.

Case 1, working on reduction process, was seen at home on November 14th, 1918. He had been ill a few days, had marked icterus and was feeble; there was no delirium. The urine was
of a dark porter colour, containing methaemoglobin, epithelial cells and tube casts, as well as 796 millimilligrams of $\mathrm{As}_{2} \mathrm{O}_{3}$ per cells and tube casts, as well as 796 millimilligrams of $\mathrm{As}_{2} \mathrm{O}_{3}$ per $100 \mathrm{c.cm}$. On December 12th the urine contained epithelial
cells, much oxalate of lime, traces of albumin and indican, no cells, much oxalate of lime, traces of albumin and indican, no
tube casts aud less than $10 \mathrm{mmg}$. of $\mathrm{As}_{2} \mathrm{O}_{3}$ per $100 \mathrm{c.cm}$. This patient made an uninterrupted slow recovery and has not been ill since; there has been no nerve lesion.

Case 2 was seen on November 9th, 1918. He complained of malaise, and passed porter-coloured urine containing $35 \mathrm{mmg}$. $\mathrm{As}_{2} \mathrm{O}_{3}$ per $100 \mathrm{c.cm}$. No icterus was at any time evident; he stayed at home, and on December 20th his urine contained less than $10 \mathrm{mmg}$. As $\mathrm{As}_{2}$ per $100 \mathrm{c.cm}$.

Case 3, who complained of haematuria, was seen on December 5th, 1918. When admitted to hospital his urine was black 5pecific gravity 1025, acid, and albuminous; it contrined $200 \mathrm{mmg}$. $\mathrm{As}_{2} \mathrm{O}_{3}$ per $100 \mathrm{c.cm}$. His recovery was uninterrupted on January $30 \mathrm{th}$, 1919, his urine contained less than $10 \mathrm{mmg}$. of $\mathrm{As}_{2} \mathrm{O}_{3}$ per $100 \mathrm{c.cm}$. He has siuce been quite well.

Case 4, who complained of abdominal pain and vomiting, and whose skin, conjunctivae, and palate were faintly icteric, was seen on January 24th, 1919, and seut to hospital. His urine was of a deep-red burgundy colour, clear, specific gravity 1025 , and of a deep-red burgundy colour, clear, specific gravity 1025, and acid. It contained much albumin. Methaemoglobin and oxy haemoglobin were present, as well as $185 \mathrm{mmg}$. $\mathrm{As}_{2} \mathrm{O}_{3}$ per $103 \mathrm{c.cm}$. On February 26th his urine contained less than $10 \mathrm{mmg} . \mathrm{As}_{2} \mathrm{O}_{3}$ per $100 \mathrm{c.cm}$., and he made a perfect recovery. Case 5 , who had no pain and no icterus, was detected while discharging his duties in the usual routine of the reduction process. On February 13th, 1919, his urine was dark-brown in colour, acid, specific gravity 1009, and contained a good deal of albumin, a few vesical epithelial cells coloured brown, no tube casts, some fibrinous clots, some brownish granular masses, and $70 \mathrm{mmg}$. $\mathrm{As}_{2} \mathrm{O}_{3}$ per $100 \mathrm{c.cm}$. By February $27 \mathrm{th}, 1919$, the arsenic 
had been reduced to less than $10 \mathrm{mmg}$. per $100 \mathrm{c.cm} .$, and he made an uninterrupted recovery.

I am indebted to Professor Delépine, of the Public Health Laboratory, Manchester, for the analytical reports submitted, and to Mr. Thomas Callan, M.Sc., Ph.D., for help in subsequent analyses.

\section{RUP'TURED MALARIAL SPLEEN : SPLENEC- TOMY : RECOVERY.}

BY

CYRIL A. RAISON, M.B., Сh.B., Late Acting Major R.A.M.C. ('T.),

Orficer in Charge Surgical Division 33hd Stationary Hospital.

Battle wrote: "The rupture of a malarial spleen may be compared with that of an aneurysm - the rupture of a normal spleen to that of a large artery," while Lieut. Co'onel Crawford, in the Indian Medical Gazette, summarizes his extcnsive experience in a statement that "Ruptured spleens not infrequently come under the notice of surgeons in India-not as a rule in hospital during life, but after death in the subject of a judicial post-mortem examination. 'The injury is always of grave importance and practically always fatal." 'The late Surgeon-General Coull-Macisenzie stated that 68.9 per cent. of cases of splenic rupiure end fatally within half an hour. Captain Jamison published an interesting series of six cases in the Brirish Medical Journal, September 14th, 1918, but in view of the fact that relatively few recoreries have been recorded, the following case may be of interest:

A Macedonian, 56 years old, was admitted on May zoth, 1918. He was very collapsed and complained of great abdominal pain, aggravated by movement or by coughing; his expression was extremely anxions and few words could be elicited from him. His skin was sallow, his lips were pale and slightly cyanotic. The pulse was 145 , and the respirations were 44 per minute; they were shallow, and there were signs of diffuse bronchitis. 'The abdominal wall scarcely moved and was rigid and tender generally, but particularly in the left hypochondrium. The generally knees were flexed. The splenic dullness extended to the umbilicus, and both flanks were dull on percussion. There was umbilicus, and both flanks wer

no external sign of bruising.

Operation.-Under local anaesthesia by $\frac{1}{2}$ per cent. novocain a median incision was made above the umbilicus. When the peritoneum was opened a large quantity of blood gushed forth. Morphine gr. 3 was given, and Captain A. C. Smith induced gas and oxygen anaesthesia. An oblique incision was made through the left rectus parallel to and one inch below the . costal capsule was almost completely raised from the matrix, and showed an irregular tear about four inches long, through which blood was coming. In consequence of adhesions to the diaphragm it was impossible to bring the spleen $u_{p}$, and therefore (with considerable difficulty) the pedicle was clamped from the front. Intravenous injection of glucose and sorlium bicarbonate was made throughout the remainder of the operation. The adhesions giving considerable trouble, they were divided between clamps and ligatured after the removal of the spleen. The abdominal cavity, which contained much blood, was irrigated with warm saline solution, and a certain amount being allowed to remain inside, the and a certain amount

'l'he patient's condition was critical, but on the following day he was much improved, the pulse falling to 128 about twelve hours after the operation. He was given 10 grains of quinine four-hourly, and made steady progress, the evening pyrexia, which disappeared on the tenth day, being the only point of note. When last seen, in February, 1919, he said he had never felt better in his life; he certainly looked many years younger.

The spleen was found to be $13 \frac{1}{2}$ inches long, and $6 \frac{1}{2}$ inches The spleen was found to be $13 \frac{1}{2}$ inches long, and $6 \frac{1}{2}$ inches wide, and to weigh four inches long penetrating two inches into the substance; the capsule was raised in front. The into the substance; the capsule was raised in front. The
blood, limited above by the diaphragmatic adhesions, had burrowed beneath the capsule, which had eventually given way, a tear being produced. The blood count made on June 6 th (a week after operation) showed 3,520,000 erythrocytes, and 26,000 leucocytes. (polynuclears 67 per cent., eosinophils 4 per cent., small lymphocytes 11 per cent., large lymphocytes 9 per cent., large hyalines 9 per cent.); many red cells showed poiycent., large hya

Three days subsequent to the operation the following history was obtained from the patient's wife, but doubt is cast on its was obtained from the patient's wife, but doubt is cast on its accuracy : " He had lrad malaria for many years. Four or five
days before his operation he had been kicked in the back by a donkey, but felt little the worse and continued his ordinary work. 'During the early hours of the morning prior.to his admission he suddenly awoke with great pain in his left gide and then in his abdomen. He vomited several times."

The interesting features of this case are that the rupture occurred in a man of 56 , that the spleen was the largest $I$ can trace as having been removed in a case which subsequently recovered, and that there were massive adhesions. According to Vanverts the presence of the Iatter in splenectomies for malarial hypertrophy without rupture raises the mortality from 5.7 per cent. to 72 per cent.

\section{SYPHILIS INSONTIUM.}

$\mathbf{B Y}$

J. C. McWALTER, M.D., LL.D., M.R.I.A.,

Sometime Spectalist Sanitary OfFick R.A.a.c.

D'Arcy Power teaches that syphilis is transmitted to the fetus only at conception or in the earlier montlis of pregnaucy. Almost all the experts seem to hold the same view, and hence it may be worth while to record a case, at present under my care, which appears to prove conclusively that infection can take place in the eighth mouth of preguaucy.

It is also of great importance to have definite and scientific records of cases of syphilis insontium, because there is usually something short of conclusive proof that a case of syphilis was extragenital in origin.

My patient was a married woman in the earlier thirties with four healthy children and no history of abortion. She consulted me about an ulcer at the angle of the mouth; it was shallow and of greyish colour; at first I supposed it to be due to pyorrhoea. She expected her confinement in the following month. I prescribed soune solution of iodine with glycerin, but when she returned the following week the ulcer was no better, the submaxillary glands had become inflamed, and the whole sore began to exhibit a typically chancroid appearance. I sent her to the Pathological Laboratory at Trinity College, Dublin, and it was reported that the sore was teemiug with Spirochata pallida.

One is peculiarly prone to jump to rash conclusions in thess cases, and I presumed that the woman's husband was responsible. I interviewed and examined him, but he had no trace of the disease. It then seemed probable that the woman herself was to blame, when further investigation showed that sine had got the sore on her mouth from kissing a clild who had an acutely virulent sore on ite moutl.

On consultation, it was decided that salvarsan treatment might be risky, in view of the expected early confinement, and the patient was put on an ordinary course of mercury, cinchona, and iodides. The sore rapidly healed, and in four weeks she was delivered of a tine infant, which exhibited no signs of syphilis at birtb, or for four weeks afterwards. The child had never a primary sore.

I had begun to conclude that the infant liad escaped syphilis when the mother reported that it had commenced to look unwell, and when examined in the fifth week it showed slight but unmistakable signs of congenital syphilis. 'I'hese cleared up so rapidly under mercurial treatment that it is with great difficulty the mother can be induced to continue the treatment for her child.

Does the Spirochaeta pallida pass directly from tho maternal blood to the infant's? 'The patient would seem to prove the affirmative. This case proves, I think-

1. Infection of a mother with syphilis in the eighth month of her preguancy results in infection of the child.

2. The syphilis in the child is of - a milder form and develops later than ordinary congenital syphilis.

3. Infection of the mother with syphilis in the later months of pregnancy may have no deleterious effect on her confinement.

4. There are some cases of syphilis insontium capable of the most rigid proof.

'Professor P. LEBEAU, of the School of Pharmacy of the University of Paris, will give two advanced lectures in chemistry at the end of this month at King's College London. The first lecture, on June $28 \mathrm{th}$, at 5 p.m., will deal with the ammonium metals in organic chemistry; in the second, on June 30 th, the theoretical and practical results of the work of $M$. Moissan will be discuased. 